\title{
Os processos de Multi, Inter e Transdisciplinaridade em um Curso voltado para a Formação Continuada de Professores em Informática na Educação
}

\author{
Isaura Alcina Martins Nobre ${ }^{1,}$ Vanessa Battestin Nunes ${ }^{1}$, Rutinelli da Penha \\ Fávero $^{1}$, Tânia Barbosa Salles Gava ${ }^{1,2}$, Lydia Márcia Braga Bazet ${ }^{1}$ \\ ${ }^{1}$ Coordenadoria de Pós-graduação em Informática na Educação - Instituto Federal do \\ Espírito Santo (Ifes) Serra - ES - Brasil \\ ${ }^{2}$ Departamento de Arquivologia - Universidade Federal do Espírito Santo \\ (UFES)Vitória - ES - Brasil \\ \{isaura,Vanessa,rutinelli\}@ifes.edu.br,taniagava@gmail.com,lydiabraga@ifes.edu.br
}

\begin{abstract}
This paper aims to share experiences of planning and development of a graduate course, offered in the distance, which included the study and integration of the team in search for an educational proposal multi, inter and transdisciplinary, aiming to offer continuing education for teachers in the areas of Computing in Education.

Resumo. Este artigo tem por objetivo compartilhar as experiências de planejamento e desenvolvimento de um curso de Pós-Graduação, ofertado na modalidade a distância, que contou com o estudo e a integração da equipe em busca de uma proposta multi, inter e transdisciplinar de ensino, visando oferecer formação continuada a professores nas áreas de Informática na Educação.
\end{abstract}

\section{Introdução}

Planejar e gerir um curso não são tarefas triviais, especialmente quando se trata de cursos na modalidade a distância e quando se busca estabelecer um padrão de qualidade. No caso do curso de Pós-Graduação Lato Sensu em Informática na Educação (PIE), ofertado pelo Instituto Federal do Espírito Santo (Ifes), campus Serra, um caminho de aprendizagem, colaboração e trabalho, tem sido percorrido.

Esse curso objetiva contribuir na formação continuada de profissionais (em sua maioria professores) quanto ao uso de tecnologias no processo de ensinoaprendizagem, de forma multi, inter e transdisciplinar. Também tem como finalidade: atender aos objetivos do Sistema Universidade Aberta do Brasil (UAB) quanto a proporcionar a oferta de cursos voltados para a formação continuada de professores da educação básica e demais níveis; fomentar o desenvolvimento institucional para a modalidade de educação a distância $(\mathrm{EaD})$, bem como a pesquisa em metodologias inovadoras de ensino apoiadas pelo uso da tecnologia na educação (UAB, 2009). 
O curso teve sua primeira edição em 2010, com 120 alunos matriculados, distribuídos por quatro polos municipais. Já em 2011, em sua reoferta, houve 250 alunos matriculados distribuídos por cinco polos municipais.

O objetivo deste artigo é compartilhar os caminhos percorridos no planejamento, elaboração e desenvolvimento do curso de Pós-Graduação em Informática na Educação, em suas duas últimas edições, ofertado na modalidade a distância pela Instituição A, que contou com o estudo e a integração da equipe (gestora e de professores) em busca de uma proposta multi, inter e transdisciplinar e que permitisse aos alunos não apenas estudar assuntos teóricos, mas vivenciar os conteúdos, por meio de abordagens teórico-práticas.

\title{
2. Multi, inter e transdisciplinaridade
}

\section{Multidisciplinaridade}

A Multidisciplinaridade surge em função de um planejamento que assuma que cada um dos componentes curriculares deve trabalhar as grandes áreas, ou seja, no caso da PIE, tecnologia e educação.

A multidisciplinaridade representa a colaboração entre duas ou mais ciências ou áreas de conhecimento de forma a estabelecer a solução de um problema, sem que as disciplinas envolvidas no processo sejam elas mesmas modificadas ou enriquecidas (PIAGET, 1972). Corroborando, Pinto (2005) afirma que enquanto a pesquisa monodisciplinar se restringe a uma única disciplina e a um único campo de pesquisa, a multidisciplinar trabalha com várias disciplinas sem, contudo integrar os conceitos e metodologias.

Vemos que a colaboração entre as várias áreas do saber, no sentido de tornar mais claro o contexto no qual se apresenta um determinado problema, pode auxiliar na solução do mesmo. A multidisciplinaridade auxilia o aluno, em uma determinada disciplina, a ter um "olhar diferenciado", um olhar mais amplo ou mais detalhado com o auxílio de outras disciplinas, outras áreas de saber.

Contudo, se a multidisciplinaridade é importante por ampliar as possibilidades e visões da construção do conhecimento, ela não modifica a visão disciplinar, nem mesmo as fronteiras entre as áreas de conhecimento.

\section{Interdisciplinaridade}

A interdisciplinaridade representa o nível em que a interação entre várias disciplinas ou setores heterogêneos de uma mesma ciência é capaz de, a partir de interações reais, estabelecer certa reciprocidade no intercâmbio levando a um enriquecimento mútuo (PIAGET, 1972).

Quadros afirma que:

\begin{abstract}
A proposta interdisciplinar pressupõe a reorganização do processo de produção, difusão e aplicação do conhecimento tendo como referência, a compreensão de problemas significativos, assuntos que, para serem enfrentados, exigem saberes de naturezas diferentes e o esforço conjunto de vários campos de conhecimento e pesquisa. (2005, p. 3)
\end{abstract}

Dessa forma, entendemos que na Interdisciplinaridade há a produção de um conhecimento novo a partir de duas ou mais áreas que se integram para tal. $\mathrm{O}$ 
interdisciplinar consiste num tema, objeto ou abordagem em que duas ou mais disciplinas se relacionam para alcançar maior abrangência de conhecimento.

Ainda segundo o Instituto Paulo Freire (2011), a metodologia do trabalho interdisciplinar implica em:

$1^{\circ}$ - integração de conteúdos; $2^{\circ}$ - passar de uma concepção fragmentária para uma concepção unitária do conhecimento; $3^{\circ}$ - superar a dicotomia entre ensino e pesquisa, considerando o estudo e a pesquisa, a partir da contribuição das diversas ciências; $4^{\circ}$ - ensino-aprendizagem centrado numa visão de que aprendemos ao longo de toda a vida. (INSTITUTO PAULO FREIRE, 2011).

Acreditamos que a interdisciplinaridade é um objetivo a ser buscado, é preciso processualmente trabalhar a metodologia proposta acima e internalizar, conjuntamente as formas de trabalhar interdisciplinar.

\section{Transdisciplinaridade}

Após a crescente hiperespecialização decorrente da explosão de conhecimento, ocorrida principalmente no final do século $\mathrm{XX}$, com a consequente disciplinarização do conhecimento, os currículos voltados para a formação têm sido elaborados buscando agrupar disciplinas relacionadas a determinada área de saber.

Segundo Morin (2009), pensar globalmente é o que possibilita uma reflexão local ao indivíduo. Porém, ainda hoje permanece a fragmentação e a visão da construção do conhecimento muito específico. A consequência desta lógica impregnada em nossa Educação é que se compreende o mundo de forma isolada e parcial e, por isso, os problemas são resolvidos fora de seu contexto, gerando uma ruptura do diálogo entre o local e o global. O autor propõe, em seus estudos, o desenvolvimento do pensamento complexo, uma reforma do pensamento por meio do ensino transdisciplinar, capaz de formar cidadãos planetários, solidários e aptos a enfrentar os desafios atuais.

Para Santos que também visa a percepção dessa realidade::

É hoje reconhecido que a excessiva parcelização e disciplinarização do saber científico faz do cientista um ignorante especializado e que isso acarreta efeitos negativos. Esses efeitos são sobretudo visíveis no domínio das ciências aplicadas (SANTOS, 2006, p.74).

Para estes autores, a possibilidade de mudança desse paradigma em educação perpassa e é perpassado por mudanças sociais, porém, é claro que também há caminhos que a própria ciência da educação anda para essas mudanças, uma possibilidade de acreditamos é a transdisciplinaridade.

Piaget, já em 1972, afirmava que transdisciplinaridade envolve não só as interações ou reciprocidade entre disciplinas e/ou projetos especializados de pesquisa, mas a colocação dessas relações dentro de um sistema total, sem quaisquer limites rígidos entre as disciplinas.

Da mesma forma Nicolescu (1999, p.2) afirma que "a interdisciplinaridade ultrapassa as disciplinas, mas sua finalidade também permanece inscrita na pesquisa disciplinar". Já a transdisciplinaridade, segundo o mesmo autor, como o prefixo "trans" indica, "[...] diz respeito aquilo que está ao mesmo tempo entre as disciplinas, através das diferentes disciplinas e além de qualquer disciplina. Seu objetivo é a compreensão do mundo presente, para o qual um dos imperativos é a unidade do conhecimento" (p.2). 
A visão transdisciplinar supõe cooperação, ruptura, desvios, reflexões e a saída de um local confortável e conhecido para uma postura de abertura, erro, revisão e mudanças. Não é fácil nem há um caminho específico para isso, mas, o caminho constante de pesquisa, técnica e o debruçar sobre a complexidade.

\section{O Planejamento da PIE em uma visão multi, inter e transdisciplinar}

Dentro de uma perspectiva de aprendizado e abertura para a mudança a PIE é voltada para a formação de professores ou profissionais envolvidos com a educação. Dessa forma, para o planejamento do curso foram selecionados professores e tutores com formação em Informática e/ou Educação. Grande parte dos alunos são professores efetivos ou contratados da rede pública estadual e municipal.

O planejamento do curso, em sua primeira edição, teve início com reuniões para que todos da equipe se conhecessem e compartilhassem suas experiências com a $\mathrm{EaD}$ e em cursos dessa natureza. Também, foram apresentadas as propostas de projeto do curso e de um planejamento em uma visão multi, inter e transdisciplinar.

Todos os professores participantes destas reuniões e que se responsabilizaram pela elaboração do conteúdo das salas virtuais, passaram por uma formação específica de professores em EaD, realizada pelo Centro de Educação a Distância (Cead) do Ifes. No último componente desta formação o professor deveria planejar a sua sala virtual, em uma visão disciplinar. Estes então elaboraram o chamado mapa de atividades uma tabela na qual o professor define para cada semana de desenvolvimento de sua disciplina o tema principal, subtemas, objetivos específicos, atividades, recursos do ambiente virtual a serem utilizados (no caso, do ambiente Moodle), grau de dificuldade e pontuação da atividade, entre outros.

Ao final dessa formação foi realizada outra reunião presencial, a tentativa era começar a ir além de cada desenho disciplinar, para isso, cada professor apresentou seu mapa de atividades para que todos pudessem conhecer a proposta e colaborar com a mesma.

Passou a ser utilizada também a sala virtual de coordenação, criada no ambiente Moodle para favorecer discussões e trocas de materiais. Nessa sala foram disponibilizados: projeto do curso, atas das reuniões, mapas de atividades, cronograma do curso, entre outros. Ela foi e tem sido um importante recurso para favorecer a redução de reuniões presenciais sem perder a qualidade e a quantidade de trocas necessárias de informações e experiências entre a equipe no sentido de cooperação e colaboração no planejamento e na execução do curso.

Após reuniões e discussões nos fóruns disponibilizados na sala citada acima, os professores chegaram a uma versão multidisciplinar de seus conteúdos. Entendemos que a visão multidisciplinar ampliou a compreensão dos conteúdos e a forma de se trabalhar com eles no processo de ensino-aprendizagem.

Além disso, estas discussões reforçaram a necessidade de um planejamento interdisciplinar dada a complementaridade de conteúdos entre as disciplinas e o fato de que algumas seriam ofertadas concomitantemente, segundo o calendário do curso.

A partir de então foi realizada uma versão dos mapas de atividades contemplando agora a visão interdisciplinar possível ao grupo naquele momento. A quantidade de reuniões e as sucessivas revisões dos mapas de atividades elaborados alcançaram o objetivo principal que era o de evitar a justaposição de conteúdos e 
favorecer a realização de atividades interdisciplinares, e até mesmo de avaliações presenciais, entre disciplinas concomitantes.

Para a viabilização do planejamento transdisciplinar buscamos, em equipe, entender qual seria o tema transversal que envolveria todo o curso, e que culminou no tema "Formação de professores e o uso de tecnologias". A proposta transdisciplinar inicial foi que cada professor buscasse contemplar atividades que pudessem transpassar, e até mesmo extrapolar, as próprias disciplinas, pensando também nos contextos, nos aspectos da realidade na qual os alunos estavam inseridos, buscando que estes, por meio das reflexões, ações, pesquisas e atividades, pudessem responder a seguinte questão atravessadora: "Como posso utilizar as tecnologias para melhoria da minha prática docente, dentro da realidade local na qual estou inserido, buscando favorecer a aprendizagem?"

Todas estas experiências, também resultaram em um artigo, realizado em colaboração entre os docentes, relacionando o componente com à temática "Formação de professores para o uso de tecnologias", e a união destes artigos formaram um livro que foi disponibilizado como material didático na reedição do curso, turmas de 2011.

\section{Gestão e acompanhamento das disciplinas}

A gestão de um curso que pretende tornar possíveis mudanças de visões e de paradigmas também precisa ser uma gestão modificada. Como cita Dalmás (2010, p.28) o processo de liderança "[...] será eficaz na medida em que for comunitário e criativo, aproveitando o conhecimento e o discernimento do grupo, bem como as soluções que o mesmo apresenta". Dessa forma, para que um componente na PIE possa ser iniciado e executado são realizadas diversas reuniões sendo: reuniões para planejamento do curso com designer instrucional, pedagogo e professor conteudista; reunião inicial para apresentação de metodologia e proposta de trabalho com a participação do professor formador, tutores a distância, presenciais e pedagoga do curso; reunião intermediária para acompanhamento da tutoria realizada e busca de soluções para possíveis problemas enfrentados no decorrer do processo de ensinoaprendizagem com a participação do professor formador, tutores a distância e coordenadora de tutoria; e reunião final para fechamento do componente com a participação de professor formador, tutores a distância e coordenadora do curso.

Para cada componente da PIE são aplicados vários instrumentos de avaliação por meio de formulários web. Os alunos podem avaliar o material instrucional apresentado, atividades, avaliações, a atuação do professor e tutor a distância. Além disso, o instrumento os leva a uma reflexão quanto a sua dedicação ao estudo da disciplina e aprendizado alcançado. O professor pode avaliar todo o material elaborado e/ou utilizado na disciplina, a atuação dos seus tutores a distância. Além disso, eles fazem uma autoavaliação quanto a sua atuação: pontos positivos e pontos a melhorar. Os tutores a distância podem avaliar a disciplina e a atuação do professor na gestão da disciplina. Também fazem uma autoavaliação de sua atuação. E por último, os tutores presenciais avaliam alguns aspectos da disciplina, do professor e dos tutores a distância que atuaram em seu polo.

Existe também um formulário web denominado "Acompanhamento das disciplinas" cujo link fica disponível em toda sala virtual de disciplina. O objetivo desse instrumento é permitir que os alunos possam tecer elogios e/ou críticas a disciplina e/ou atuação de tutores e/ou professor. Nesse formulário é mantido o anonimato das postagens. Cada um dos membros da equipe de coordenação fica 
responsável por realizar o acompanhamento desse formulário em um dia específico da semana. Dessa forma, diariamente é realizada a leitura das postagens o que garante uma maior prontidão em antever ou em buscar a solução de possíveis problemas.

Além do já exposto, a equipe de coordenação se reúne semanalmente. Nessas reuniões, possíveis problemas identificados, por meio das várias reuniões realizadas para planejamento e acompanhamento da execução das disciplinas ou por meio dos instrumentos de avaliação, são discutidos e os encaminhamentos necessários para a solução dos mesmos são definidos conjuntamente.

\section{Relatos sobre o Planejamento Realizado}

No sentido de buscar investigar o alcance do planejamento interdisciplinar elaboramos um questionário por meio de formulário web criado com algumas questões dentre as quais destacamos:

- Você identificou ações interdisciplinares no curso de pós-graduação em informática na educação? Em caso afirmativo, dê um exemplo:

- Essas ações foram positivas para sua aprendizagem?

- A partir de sua realidade cotidiana, como as tecnologias refletidas e aprendidas no curso, podem ser revisitadas e aplicadas em sua prática profissional? Você poderia exemplificar essa articulação observada?

Vale destacar que este questionário foi aplicado ao final do curso nas turmas de 2010 e que dos 84 alunos finalistas tivemos 53 respondentes. Essa porcentagem de, aproximadamente, 63\% deve-se ao fato dos alunos quando da aplicação do mesmo também estavam envolvidos com a elaboração dos Trabalhos de Conclusão de Curso (TCC). O questionário concentrou questões relacionadas à interdisciplinaridade por percebermos que o conceito de transdisciplinaridade ainda não estava claro para os mesmos.

Para a questão "Você identificou ações interdisciplinares no curso de pósgraduação em informática na educação?" todos os 53 respondentes afirmaram que SIM. Destacamos a seguir alguns extratos expostos em quadros e em itálico para que seja dado o destaque necessário.

A consciência da interdisciplinaridade fica visível nas colocações dos alunos, como os seguintes exemplos: Em quase todas as disciplinas paralelas, observei a interdisciplinaridade. No entanto, a que particularmente vi como mais intensa foi a interessante combinação entre "Projetos de Aprendizagem baseados no uso de novas tecnologias" e "Software Educacional e Objetos de Aprendizagem", pois o projeto de aprendizagem feito ao final do percurso foi totalmente baseado no conteúdo da disciplina de software educacional.

Uso de Mapas Conceituais como ferramenta de aprendizagem - magistral abordagem, trouxe uma nova forma de pensar.

Acessibilidade e Informática na Escola Inclusiva - sensível e tocante. Uma nova forma de ver o mundo e isso, com certeza, será refletido em meu ambiente profissional. Todas as outras foram maravilhosas, mas, essas duas se destacaram.

As disciplinas sempre que podiam trabalhavam o conteúdo de maneira interdisciplinar, ou seja, cada disciplina desenvolvia um eixo do conhecimento sobre determinado conteúdo. 
Sempre buscando relações entre si. Chegamos a construir um curso através de um blog onde diversos temas foram trabalhados interdisciplinarmente. A Acessibilidade na gestão desnudou as dificuldades em atender alunos portadores de NEE e permitiu que buscássemos soluções, através dos vídeos maravilhosos da escola de zagosrsky e do conectivismo de Lèvy, cuja teia nos engendrou e relacionou os conteúdos das três disciplinas com muita propriedade. Houve outros momentos, porém, agora fica difícil de lembrar.

Podemos perceber que os alunos construíram significações sobre o conceito de interdisciplinaridade, já aqui aparece nas falas a significação positiva acerca da aprendizagem resultada dessas experiências.

Ainda quanto às ações terem sido ou não positivas para a sua aprendizagem, não houve negativas. Destacamos alguns relatos:

Sim. Com toda certeza essa abordagem inédita em minha história acadêmica teve reflexos bastante positivos e será relevante em minha carreira profissional.

Sim. Pois, através da interdisciplinaridade é possível aprender de forma ampla os diversos conteúdos que estão relacionados, de forma clara e objetiva.

Com certeza foram positivas e na prática profissional, mesmo que os recursos, atualmente, não sejam positivos, será voltada para uma busca constante, qualificada e crítica e posteriormente não a espera, e sim, para a busca constante, transformadora, contestadora para o que parece conservador e tradicional, em uma perspectiva sempre para a educação "contemporaneamente digital".

Mesmo entendendo que haviam sido importantes e significativas, as experiências resultantes das ações interdisciplinares, faltava uma forma de descrição dessa experiência. Pela formação inicial, que entendemos como mais fragmentada e partimentada, a visão fica pouco clara quanto aos efeitos e ganhos da interdisciplinaridade. Sabe-se que a experiência acontece e é boa, mas não se sabe exatamente quais são essas experiências e seus impactos.

Destacamos ainda alguns relatos dos alunos sobre a apropriação dessas tecnologias, aprendidas e/ou revisitadas no curso, em sua prática docente:

Já tenho utilizado vários conceitos aprendidos ao longo do curso em meu ambiente de trabalho, que é exclusivamente de suporte em ambiente computacionais. Desde mapas conceituais, fóruns de trocas de ideias, passando ainda por técnicas de apresentação. Pretendo, vez por outra, voltar ao conteúdo que salvei em documentos e reaprender os conceitos e aplicações, com novas luzes. Ainda, quero fazer novos estudos nos próximos anos.

Sim. A utilização do blogger na escola que ja estou colocando em prática, os professores postam conteúdos os alunos contribuem com pesquisas e formam um ambiente escolar utilizando a internet colaborando para o crescimento de todos e a união entre professor $e$ aluno. 
Sim, no decorrer do curso, já vimos conversando com a gestora e as técnicas pedagógicas, mostrando que o que eu aprendia poderia contribuir com as colegas na revisão das práticas e dos conteúdos, mostrando o quanto é agradável usar ferramentas diversificadas no dia a dia da escola. É claro que não vamos mudar o mundo mas, podemos começar a melhorar a nossa escola, oferecendo aos alunos a oportunidade de mostrarem suas habilidades e conhecimentos que, muitas vezes, ultrapassam os nossos na habilidade de utilizar as diversas Tecnologias, permitindo-Ihes difundir suas criações através de blogs, fotologs, portfólios, murais, apresentações de curtas outros recursos que a informática oferece.

Todas as tecnologias aprendidas e refletidas auxiliam a aprendizagem e a formação de conhecimentos, porém pela falta de internet no laboratório de informática de minha escola ainda não podemos usufruir de todo conhecimento adquirido, mas assim que for estalada a internet, tentarem socializar o conhecimento que adquirir durante a pós para o desenvolvimento dos alunos.

A práxis envolvida nas reflexões apresentadas mostram uma possível relação para além das disciplinas. Um impacto que, longe de ser pragmatista, mostra-se no cotidiano.

Além da visão do aluno, também foi importante ouvir os docentes envolvidos para percepção das mesmas questões e outras que modificam as questões para a tentativa da apreender aspectos possíveis aos professores. Para tanto, também foi aplicado um questionário via formulário web, mas a principal fonte de dados para análise foi a realização de entrevistas. Destacamos algumas falas quanto ao planejamento interdisciplinar realizado no curso:

Eu achei excelente esse projeto, quando surgiu esse projeto, na época eu era muito ocupada não pude acompanhar ele no início, porque você tem que estar predestinado, com predisposição pra realmente fazer porque ele dá mais trabalho, é muito mais fácil cada um na sua casinha. O desafio na verdade é você agrupar pessoas que queiram fazer, isso que é o mais desafiador.

Para a interdisciplinaridade o que eu penso é isso, ter conhecimento das duas disciplinas e montar atividades que realmente estejam relacionadas. É você acabar com aquela ideia da disciplina segmentada. Eu acho que por mais que a gente fale que o professor tem que conhecer o PPP do curso, o planejamento das outras disciplinas, eu acho que vai além disso. Ele realmente tem que conhecer o que está acontecendo em termos de conteúdo, de aprendizagem.

[...] achei bem interessante até a motivação dos alunos. E os trabalhos finais eles eram mais, não ficava aquela coisa uma prova, ou uma coisa solta. Como eu não via o outro lado, o que tava rolando na outra disciplina durante o trabalho eu tinha uma ideia do que eles estavam tendo. Então eu acho que os alunos se sentem muito mais motivados com esse tipo de trabalho, aonde eles vêm o casamento de dois conteúdos diferentes.

$\mathrm{Na}$ fala docente temos a vibração de uma processual ação que aparece em sucesso de aprendizagem. A interdisciplinaridade aparece, principalmente, como ferramenta de sucesso. Também buscamos identificar o que eles entendiam ser um curso transdisciplinar. Os relatos são mais complexos e, em alguns momentos, pouco evidentes. Talvez por causa da dificuldade de conceituação e mesmo de vivência de experimentos transdisciplinares. Destacamos os seguintes relatos: 
Porque um curso que se diz interdisciplinar e transdisciplinar ele não pode em cada disciplina ter um universo diferente. Eu acho que se eles construíssem uma coisa única mesmo incluindo cada vez mais coisas diferentes mas com um eixo comum. Eles iriam crescer mais.

Entendo que a transdisciplinaridade é processual, porque ainda temos fronteiras bem definidas das disciplinas. Então, estamos buscando a transdisciplinaridade. Um exemplo seria o uso dos conhecimentos das várias disciplinas para a realização do PA e a utilização desse PA exigida na disciplina da pós em uma instituição escolar dos alunos.

Com base na análise dos dados coletados por meio da aplicação de questionários e entrevistas, entendemos que o trabalho coletivo entre professores e tutores tem conseguido alcançar a interdisciplinaridade, por meio de um planejamento sistemático e um currículo ajustado em suas atividades que buscam relacionar conteúdos dentre as várias disciplinas.

Quanto à transdisciplinaridade percebemos que um conceito, uma visão de planejamento, novo para muitos dos professores na primeira edição do curso apareceu de forma incipiente em algumas atividades que buscavam levar o aluno a relacionar o uso da tecnologia a sua prática docente dentro de sua realidade. Já na segunda edição, os professores têm buscado alternativas para que efetivamente o aluno consiga fazer com que esse conhecimento reflita diretamente na prática docente do aluno. Para uma próxima edição, hoje em fase de planejamento, temos a proposta da elaboração de um blog individual pelo aluno que irá ser alimentado durante o andamento do curso sempre procurando responder a questão transdisciplinar do curso e deixar visível a crescente e processual modificação e impactos na aprendizagem.

\section{Conclusão}

No desenvolvimento do planejamento e no desenvolvimento da PIE podemos elencar diversos pontos e muitas experiências de aprendizagens, dentre os quais destacamos: o planejamento das disciplinas com a contribuição de todos, o que despertou um comprometimento maior de toda a equipe com a proposta do curso; a contribuição processual das atividades multi e interdisciplinares no processo de ensino e aprendizagem; a comunicação mais efetiva entre tutores presenciais e professores; a comunicação/parceria estabelecida entre tutores de disciplinas concomitantes devido às atividades interdisciplinares; a experiência de vários de nossos professores na atuação também como tutores a distância em outras disciplinas; ajustes de percurso com base na análise das diversas avaliações aplicadas sobre a tutoria e as disciplinas ofertadas; e o desenvolvimento cooperativo de um manual de procedimentos, construído para apoiar todos os componentes da equipe, constando procedimentos que foram pensados para todos terem visão das ações da gestão do curso.

Apesar de todo o engajamento da equipe, não só de coordenação, mas também de professores e tutores, ainda identificamos alguns desafios na metodologia adotada. Conforme citam Botelho e Vicari,

$\mathrm{Na}$ EaD, em particular, há especificidades: por um lado, a heterogeneidade do público a ser atendido - a EaD geralmente é uma modalidade utilizada para atuar em extensas áreas geográficas e grandes populações - e, por outro, as necessidades de uma certa padronização dos instrumentos de aprendizagem para viabilizar a gestão do sistema. Isso torna mais complexo o sistema educacional e reforça o desafio. (2009).

Dessa forma, temos o grande desafio que é pensar na formação de professores de uma forma multi, inter e transdisciplinar. Buscar relacionar os vários conhecimentos para responder as questões que se referem à temática como um todo $\mathrm{e}$ 
que por isso mesmo ultrapassam as fronteiras das disciplinas. E para, além disso, tentar conciliar as problemáticas com a realidade do nosso aluno (na sua maioria professores) lançando mão de suas crenças e valores. Entendemos que apesar de trabalhoso buscar superar esse desafio tem proporcionado grandes conquistas e aprendizagens tanto para alunos como para os professores e equipe de coordenação do curso.

\section{Referências}

BOTELHO, F. V. U.; Vicari, R. M. "A Qualidade dos Processos Interativos como Chave para a Avaliação da Efetividade de Cursos a Distância". Revista Brasileira de Informática na Educação, Volume 17, Número 1, 2009.

DALMÁS, Angelo. Planejamento participativo na escola. $16^{\mathrm{a}}$. Ed. Petrópolis, RJ: Vozes, 2010.

INSTITUTO Paulo Freire. "Inter-Transdisciplinaridade e Transversalidade". Instituto Paulo Freire/Programa de Educação Continuada. Disponível em: http://www.inclusao.com.br/projeto_textos_48.htm. Acesso em: 25 jul. 2011.

MORIN, Edgar. "Arte, cultura e ciência unidas no discurso do pensador que aposta na transdisciplinaridade". Disponível em: $\leq$ http://www.universia.com.br/materia/imprimir.jsp?id=9756>. Acesso em: 09 ago. 2009.

NICOLESCU, Basarab. "Um novo tipo de conhecimento - transdisciplinaridade. 1o Encontro Catalisador do CETRANS - Escola do Futuro - USP". Itatiba, São Paulo, 1999.

Disponível

em: http://www.ufrrj.br/leptrans/arquivos/conhecimento.pdf . Acesso em: 22 jul. 2011.

PIAGET, J. "The epistemology of interdisciplinary relationships". in L. Apostel,G. Berger, A. Briggs, and G. Michaud, eds. Interdisciplinarity: problems of teaching and researchin universities. Paris: Organization for Economic Cooperation and Development (OECD). 1972, p. 127-140.

QUADROS, T., MARTINS, J. S. B., "A Prática Interdisciplinar em Programas de Educação a Distância num Cenário de Novas Tecnologias da Informação e Comunicação” In: XVI Simpósio Brasileiro de Informática na Educação. 2005. UFJF. Anais do XVI Simpósio Brasileiro de Informática na Educação, 2005. Disponível em: < http://www.br-ie.org/pub/index.php/sbie/article/view/419>. Acesso em: 09 ago. 2012.

SANTOS, Boaventura de Sousa. "Um discurso sobre as ciências". $4^{\mathrm{a}}$ edição. Cortez: São Paulo, 2006.

SOMMERMAN, Américo. "Complexidade e Transdisciplinaridade". I Encontro Brasileiro de Estudos da Complexidade. 11 a 13 e julho de 2005, Curitiba/PR. Disponível em: 〈http://www.ufrrj.br/leptrans/arquivos/complex.pdf $>$. Acesso em 22 jul. 2011.

UAB - Universidade Aberta do Brasil. "O que é”. Disponível em: $<$ http://www.uab.capes.gov.br/index.php?option $=$ com_content\&view=article\&id= $6 \&$ Itemid $=18>$. Acessado em 03 de mai de 2012. 